\title{
Oxidative stress induced by carboplatin promotes apoptosis and inhibits migration of $\mathrm{HN}-3$ cells
}

\author{
PEI-JIE HE ${ }^{1,2^{*}}$, RUI-FENG GE ${ }^{3 *}$, WEN-JING MAO ${ }^{1}$, PHIL-SANG CHUNG ${ }^{4}$, JIN-CHUL AHN ${ }^{4}$ and HAI-TAO WU ${ }^{1}$ \\ ${ }^{1}$ Department of Otolaryngology-Head and Neck Surgery, Shanghai Key Clinical Disciplines of Otorhinolaryngology, \\ Eye and ENT Hospital of Fudan University, Shanghai 200031; ${ }^{2}$ Department of Otolaryngology, \\ Shanghai Public Health Clinical Center, Fudan University, Shanghai 201508; \\ ${ }^{3}$ Department of Otolaryngology-Head and Neck Surgery, The Affiliated Hospital of Qingdao University, \\ Qingdao, Shandong 266003, P.R. China; ${ }^{4}$ Department of Otolaryngology-Head and Neck Surgery, \\ Beckman Laser Institute Korea, Dankook University, Cheonan, South Chungcheong 330-715, Republic of Korea
}

Received December 20,2017; Accepted September 7, 2018

DOI: $10.3892 / \mathrm{ol} .2018 .9563$

\begin{abstract}
Laryngeal squamous cell carcinoma (LSCC) is currently a serious public health problem in China; thus, it is urgent to identify effective treatment strategies for this disease. Previous studies demonstrated that reactive oxygen species (ROS) serve important roles in the apoptosis of LSCC cells. It has also been indicated that carboplatin (CBDCA), a second-generation platinum compound with broad antineoplastic properties, is able to induce oxidative stress to produce ROS, which in turn promotes apoptosis. Thus, the present study investigated if CBDCA is cytotoxic in LSCC cells due to the oxidative stress caused by ROS. Therefore, an MTT assay was performed to determine the cell viability of HN-3 LSCC cells following treatment with different doses of CBDCA. Subsequently, the expression levels of ROS and the rate of apoptosis/necrosis were evaluated in the cells. Following this, the HN-3 cells were co-treated with CBDCA and glutathione $(\mathrm{GSH})$ or $\mathrm{H}_{2} \mathrm{O}_{2}$, followed by an MTT assay, a cell migration assay and western blot analysis. The results demonstrated that CBDCA reduced the viability of HN-3 cells in a time- and dose-dependent manner and promoted the production of ROS and apoptosis at certain doses. Additionally, the combination treatment of CBDCA and $\mathrm{H}_{2} \mathrm{O}_{2}$ enhanced the inhibitory effects of CBDCA on cell viability and migration ability, and promoted apoptosis in HN-3 cells; whereas the combined treatment of CBDCA and GSH exerted opposite effects. The results of the present study
\end{abstract}

Correspondence to: Professor Hai-Tao Wu or Dr Pei-Jie He, Department of Otolaryngology-Head and Neck Surgery, Shanghai Key Clinical Disciplines of Otorhinolaryngology, Eye and ENT Hospital of Fudan University, 83 Fenyang Road, Shanghai 200031, P.R. China

E-mail: haitaowu_ent@163.com

E-mail:hepj2002@sina.com

${ }^{*}$ Contributed equally

Key words: laryngeal squamous cell carcinoma, carboplatin, reactive oxygen species, oxidative stress, apoptosis demonstrated that CBDCA promotes the apoptosis of $\mathrm{HN}-3$ cells through accumulation of ROS, which may provide a novel treatment strategy for treating LSCC.

\section{Introduction}

Laryngeal carcinoma (LC), the second most common type of head and neck cancer, is currently a serious public health problem in China $(1,2)$. Among its subtypes, laryngeal squamous cell carcinoma (LSCC) accounts for 95-98\% of LC cases, signifying that LSCC has become a public health problem globally (1-4). Additionally, the American Cancer Society demonstrated that the incidence and mortality rate of LSCC are gradually increasing annually in USA (5). Therefore, it is of notable importance to develop more effective treatment strategies for this disease. The traditional and standard therapy for LSCC is a combination of surgery and chemotherapy or radiotherapy, but the clinical outcome has not demonstrated notable improvement in patient survival rates, despite advancements in treatment methods $(6,7)$. The low survival rate may be due to the strong migration ability of LSCC cells, which can result in recurrence and metastasis (8).

Numerous previous studies have demonstrated that reactive oxygen species (ROS) serve important roles in the development of a number of cancer types, including colorectal, breast, oral, gastric, colon, cervical and prostate cancer, and particularly in LSCC (9-15). However, the excessive accumulation of ROS can cause cancer cell apoptosis and necrosis, resulting in antitumor effects in these cancer types $(9,12,14)$. Therefore, it may be possible to utilize the dual effects of ROS to develop an effective therapeutic method for LSCC. For example, our research group reported that the excessive production of ROS triggered by 9 -hydroxypheophorbide $(9-\mathrm{HPbD})$ causes endoplasmic reticulum stress and oxidative stress, which promotes the apoptosis of human LSCC HN-3 cells (16). Additionally, it was determined that the combined treatment of CBDCA and 9-HPbD with reducing effective dosage of the anticancer drugs exhibited significant cytotoxicity in LSCC cells with a limited number of side effects and low toxicity in normal cells (17). A study by Baek et al (18) demonstrated that ROS induced by 
ascorbic acid resulted in the activation of the protein kinase $\mathrm{C}$ signaling pathway and cytosolic calcium signaling, causing the necrosis of Hep2 LSCC cells.

Carboplatin (CBDCA) is a well-known second-generation platinum anticancer drug that has been frequently used to treat various cancer types, including bladder cancer and malignant melanoma, due to its broad-spectrum anticancer properties and low cost (19). Additionally, it has reduced toxicity in the ear, kidney and nervous system compared with first-generation drugs, including cisplatin. Due to its toxicity to the kidney and ear, and numerous side effects, including emesis, nausea and cumulative myelosupression, as well as its low tolerance for long-term use $(20,21)$, it is commonly used in combination with radiotherapy or surgery for cancer treatment $(22,23)$. The molecular mechanisms underlying its antitumor effects depend upon binding to DNA in the nucleus, which blocks DNA synthesis, causing apoptosis or necrosis (24). However, Cheng et al (25) reported that CBDCA could also induce oxidative stress to produce ROS, which in turn promoted apoptosis in cardiomyocytes. Based on these results, it was postulated that CBDCA is cytotoxic in LSCC cells due to the oxidative stress caused by ROS, which promotes cancer cell apoptosis. Additionally, one previous study demonstrated that the generation of ROS upon the treatment of LSCC cells with CBDCA to some extent, but further direct evidence is required (26).

In the present study, it was determined if CBDCA had antitumor effects in LSCC cells and the underlying molecular mechanisms were assessed. Therefore, the viability, expression of ROS, and degree of apoptosis or necrosis in HN-3 cells were evaluated following treatment with various doses of CBDCA. HN-3 cells were also treated with CBDCA combined with glutathione $(\mathrm{GSH})$ or $\mathrm{H}_{2} \mathrm{O}_{2}$, following which their viability, migration ability and apoptosis were evaluated.

\section{Materials and methods}

Materials. The HN-3 cell line was obtained from the Asan Medical Center (Seoul, South Korea) (27). Hoechst 33342 dye, MTT and propidium iodide (PI) were purchased from Sigma-Aldrich (Merck KGaA, Darmstadt, Germany). CBDCA was purchased from Selleck Chemicals (Houston, TX, USA). Antibodies against cleaved caspase-3 (rabbit, cat. no. AB3623), cleaved poly(ADP-ribose) polymerase (PARP; rabbit, cat. AB3620) were purchased from Merck KGaA (Darmstadt, Germany); goat anti-epidermal growth factor receptor (EGFR; cat. no. sc-03-G; dilution 1:200) and phosphorylated c-Jun (p-c-Jun; cat. no. sc-99) were from Santa Cruz Biotechnology, Inc. (Dallas, TX, USA); rabbit anti-GAPDH polyclonal antibody (cat. no. ab9485; dilution 1:2,000) was supplied by Abcam (Cambridge, UK). 2',7'-dichlorodihydrofluorescein diacetate ( $\mathrm{H}_{2}$ DCFDA; D399) was purchased from Molecular Probes (Thermo Fisher Scientific Inc., Waltham, MA, USA).

Cell culture. The HN-3 human LSCC cell line was derived from a 63-year-old male patient with previously untreated LSCC (27). Cells were cultured in a cell incubator at $37^{\circ} \mathrm{C}$ in an atmosphere containing 5\% $\mathrm{CO}_{2}$ in RPMI-1640 medium (Hyclone; GE Healthcare Life Sciences, Logan, UT, USA) supplemented with $10 \%$ fetal bovine serum (Hyclone; GE Healthcare Life Sciences) and 1\% penicillin/streptomycin. The culture medium (RPMI-1640) was replaced every 3 days.

Cell viability assay. An MTT assay was performed to analyze cell viability. Briefly, when $\mathrm{HN}-3$ cell confluence reached $90 \%$, the cells were seeded into 96 -well plates at a density of $5 \times 10^{3}$ cells/well and further cultured in a cell incubator overnight at $37^{\circ} \mathrm{C}$. Subsequently, the indicated doses of CBDCA (0-5.0 mg/ml), GSH (5 mM) or $\mathrm{H}_{2} \mathrm{O}_{2}(0.2 \mathrm{mM})$ were added to the cells, followed by further incubation in a cell incubator in an atmosphere containing $5 \% \mathrm{CO}_{2}$ at $37^{\circ} \mathrm{C}$ for 0,24 or $48 \mathrm{~h}$. Following this, $50 \mu \mathrm{l}$ MTT solution $(2 \mathrm{mg} / \mathrm{ml})$ was added to the wells and the plates were further incubated for $2 \mathrm{~h}$ at $37^{\circ} \mathrm{C}$. Lastly, the Thermo Scientific Varioskan Flash Multimode Reader was used to measure the absorbance at $540 \mathrm{~nm}$. Cell viability was calculated according to the following equation: Cell viability $(\%)=($ mean absorbance in the treatment group/mean absorbance in the control group) $\mathrm{x} 100$.

Detection of ROS. For ROS detection by confocal microscopy as previously described (26), HN-3 cells were cultured on glass-bottom 35-mm dishes. Subsequently, $24 \mathrm{~h}$ after treatment with CBDCA, GSH or $\mathrm{H}_{2} \mathrm{O}_{2}$, as aforementioned, the cells were incubated with $2 \mu \mathrm{M} \mathrm{H}_{2}$ DCFDA in culture medium at $37^{\circ} \mathrm{C}$ for $30 \mathrm{~min}$. Following this, the cells were gently washed twice with Dulbecco's PBS. Images were collected using a $488 \mathrm{~nm}$ excitation light from the argon laser, a $560 \mathrm{~nm}$ dichroic mirror and a 505-550 $\mathrm{nm}$ band pass barrier filter. A total of 3 random fields were selected for imaging and conducting statistical analyses to measure the ROS concentration.

Hoechst 33342 and PI double staining. The HN-3 cells (cell confluence, $80-90 \%$ ) were seeded into $3.5-\mathrm{cm}$ dishes, and then treated with $\mathrm{CBDCA}$, GSH or $\mathrm{H}_{2} \mathrm{O}_{2}$, as aforementioned. After $24 \mathrm{~h}$ at $37^{\circ} \mathrm{C}$, the cells were incubated with Hoechst 33342 $\left(2 \mu \mathrm{g} / \mathrm{ml}\right.$ ) for $30 \mathrm{~min}$ at $37^{\circ} \mathrm{C}$, following which the old medium was replaced with fresh RPMI-1640 medium. Subsequently, the cells were incubated with PI $(2 \mu \mathrm{g} / \mathrm{ml})$ for $10 \mathrm{~min}$ at $37^{\circ} \mathrm{C}$. Finally, the stained cells were observed using a laser scanning confocal microscope (Laser Microdissection Systems Leica LMD6500 and LMD7000; Leica Microsystems GmbH, Wetzlar, Germany) to determine the apoptosis and necrosis levels of HN-3 cells. A total of 3 random fields were selected for imaging and conducting statistical analyses to confirm the relative apoptosis/necrosis rate.

Cell migration assay. In brief, the HN-3 cells were seeded (cell confluence, $80-90 \%$ ) into 24-well plates and reference points near the wound were marked to ensure the use of the same area for image acquisition on the plates. After a $24 \mathrm{~h}$ incubation at $37^{\circ} \mathrm{C}$, confluent monolayers of the HN-3 cells were wounded using a $200 \mathrm{ml}$ pipette tip to create a straight line. Following 2 washes with PBS, indicated doses of CBDCA (0.04 or $0.08 \mathrm{mg} / \mathrm{ml})$, GSH $(5 \mathrm{mM})$ or $\mathrm{H}_{2} \mathrm{O}_{2}(0.2 \mathrm{mM})$ were added to the cells, and then the cells were incubated in a cell incubator in an atmosphere containing $5 \% \mathrm{CO}_{2}$ at $37^{\circ} \mathrm{C}$ for $36 \mathrm{~h}$. The wound width (initial $1.2 \mathrm{~mm}$ ) was measured at four redefined locations when the wound was produced and after 12, 24 and 


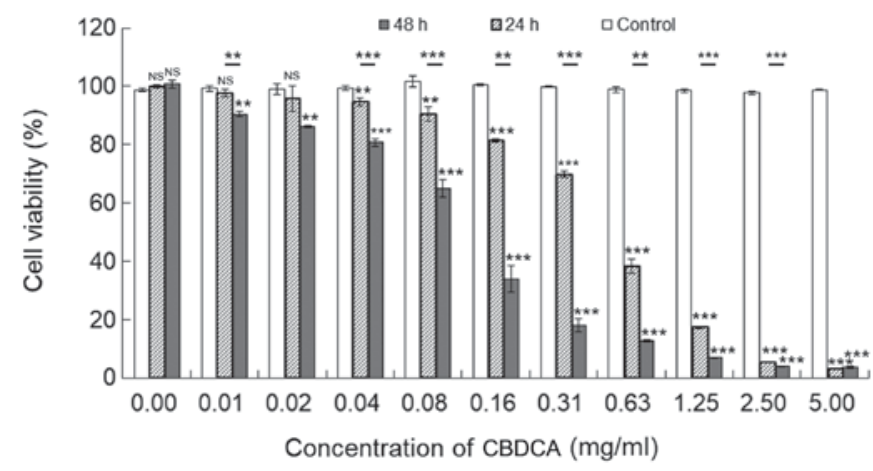

Figure 1. CBDCA inhibits the cell viability of HN-3 cells in a dose- and time-dependent manner. The human laryngeal squamous carcinoma cell line HN-3 was seeded into 96-well plates. Subsequently, the HN-3 cells in these plates were treated with the indicated doses of CBDCA for 0,24 or $48 \mathrm{~h}$ Afterwards, the cell viabilities were detected using MTT assays. Cell viability was calculated according to the following equation: Cell viability $(\%)=($ mean absorbance in the treatment group/mean absorbance in the control group) $\mathrm{x} 100$. The data were expressed as mean \pm standard deviation, ${ }^{* *} \mathrm{P}<0.01$ and ${ }^{* * * *} \mathrm{P}<0.001$ vs. control or 48 vs. 24 h. CBDCA, carboplatin; NS, not significant.

$36 \mathrm{~h}$. The distances between the two edges of the wound were measured at the reference points and statistically analyzed.

Western blot analysis. The HN-3 cells were seeded (cell confluence, $80-90 \%$ ) into 6-cm dishes. Following cells reaching $90 \%$ confluence, indicated doses of CBDCA (0.04 or $0.08 \mathrm{mg} / \mathrm{ml})$, GSH $(5 \mathrm{mM})$ or $\mathrm{H}_{2} \mathrm{O}_{2}(0.2 \mathrm{mM})$ were added, and then the cells were incubated in an incubator for $24 \mathrm{~h}$ at $37^{\circ} \mathrm{C}$. Subsequently, the cells were collected and lysed in radioimmunoprecipitation assay buffer (Sigma-Aldrich; Merck $\mathrm{KGaA}$ ), and total protein was obtained following centrifugation at $4^{\circ} \mathrm{C}$ at $14,000 \mathrm{x}$ g for $30 \mathrm{~min}$. Following the protein concentrations being measured using a BCA kit (Beyotime Institute of Biotechnology, Jiangsu, China), the proteins were separated using 10\% SDS-PAGE and then electrophoretically transferred onto polyvinylidene difluoride membranes. Subsequently, the membranes were incubated overnight at $4^{\circ} \mathrm{C}$ with 1:1,000 diluted primary antibodies conjugated with horseradish peroxidase (HRP), subsequent to being blocked in 5\% non-fat milk in Tris-buffered saline with Tween $20(0.5 \%)$ (TBST) for $1 \mathrm{~h}$ at room temperature, washed 3 times with TBST, and then incubated with HRP-conjugated goat anti-rabbit $\operatorname{IgG}$ polyclonal secondary antibody $(1: 2,000$; Abcam, Cambridge, UK, ab97051) at room temperature for $2 \mathrm{~h}$. The proteins were visualized using SuperSignal West Pico Chemiluminescent Substrate (Thermo Fisher Scientific, Inc.), according to the manufacturer's protocols. Membranes were scanned with ImageJ (k 1.45; National Institutes of Health, Bethesda, MD, USA) to quantify the band intensity.

Statistical analysis. All of the experiments in the present study were repeated at least three times, and the final results were expressed as the mean \pm standard deviation. Significant differences among experimental groups were analyzed by one-way analysis of variance followed by the Least Significant Difference post-hoc test. Statistical analyses were performed using SPSS 11.5 software (SPSS, Inc., Chicago, IL, USA). $\mathrm{P}<0.05$ was considered to indicate a statistically significant difference.

\section{Results}

CBDCA inhibits the viability of $\mathrm{HN}-3$ cells in a dose- and time-dependent manner. To determine if CBDCA has antitumor effects in LSCC, an MTT assay was conducted to detect the viability of HN-3 human LSCC cells following treatment with different doses of CBDCA for 0,24 or $48 \mathrm{~h}$. As depicted in Fig. 1, the viability of $\mathrm{HN}-3$ cells significantly decreased as the concentration of CBDCA increased from $0-5 \mathrm{mg} / \mathrm{ml}(\mathrm{P}<0.05$, excluding a number of cases when the concentration of CBDCA was 0.01 and $0.02 \mathrm{mg} / \mathrm{ml}$ ). Furthermore, treatment of CBDCA for $48 \mathrm{~h}$ resulted in increased inhibitory effects on cell viability, compared with treatment for $24 \mathrm{~h}$. Therefore, CBDCA suppressed the viability of $\mathrm{HN}-3$ cells in dose- and time-dependent manners.

CBDCA promotes the production of ROS and apoptosis of $H N-3$ cells. Numerous studies have reported that CBDCA exerts antitumor effects in a number of malignant tumor types, including lung, non-small cell lung, cervical and ovarian cancer, by inducing the apoptosis of these cancer cells, which is mediated by the accumulation of ROS (19,28-32). Therefore, whether this molecular mechanism also applies to HN-3 cells was investigated. Firstly, $\mathrm{H}_{2}$ DCFDA imaging was used to detect the expression level of ROS following treatment with CBDCA for $24 \mathrm{~h}$. The treatment time was selected because as the upstream molecule of the function of CBDCA, the production of ROS occurred relatively early which could be observed distinctly at the time point of $24 \mathrm{~h}$. As depicted in Fig. 2A, it was determined that the intensity of green fluorescence released by HN-3 cells was increased as the concentration of CBDCA increased from $0-0.64 \mathrm{mg} / \mathrm{ml}$, and then declined as the concentration of CBDCA further increased from $0.64-5 \mathrm{mg} / \mathrm{ml}$. This effect was confirmed by statistical analysis $(\mathrm{P}<0.01$ for $0.16,0.32,0.64$ and $1.25 \mathrm{mg} / \mathrm{ml}$ ) (Fig. 2B). Subsequently, Hoechst 33342/PI double staining was performed to evaluate the apoptosis and necrosis levels in HN-3 cells following treatment with CBDCA. Similar to the aforementioned results, the apoptosis of HN-3 cells first increased with CBDCA concentrations ranging from $0-0.64 \mathrm{mg} / \mathrm{ml}$, and then decreased with CBDCA concentrations ranging from $0.64-5 \mathrm{mg} / \mathrm{ml}$, while the necrosis level of HN-3 cells increased during this period (Fig. 2C and D). Thus, these data demonstrated that CBDCA promoted the production of ROS and subsequent apoptosis of HN-3 cells in a dose-dependent manner within a certain concentration range.

Combination treatment with GSH inhibits the suppressive effects of CBDCA on $\mathrm{HN}-3$ cell proliferation. To confirm the aforementioned results demonstrating that CBDCA may increase the accumulation of ROS, causing the apoptosis of HN-3 cells, HN-3 cells were treated with CBDCA and GSH or $\mathrm{H}_{2} \mathrm{O}_{2}$ for $48 \mathrm{~h}$ prior to testing the cell viability with an MTT assay. Additionally, incubation time was selected as it was the most beneficial for observing the change induced by the regulation of ROS production whilst maintaining a $\sim 60 \%$ cell viability post-treatment. Furthermore, the application of $0.08 \mathrm{mg} / \mathrm{ml} \mathrm{CBDCA}$ resulted in the positive and negative regulation of production of ROS by $\mathrm{H}_{2} \mathrm{O}_{2}$ and $\mathrm{GSH}$, respectively, thus benefitting the observation of the change in the following experiments. In addition, based on the concentration screening experiments (data not shown), 
A $\quad$ CBDCA : $\mathrm{mg} / \mathrm{ml}$

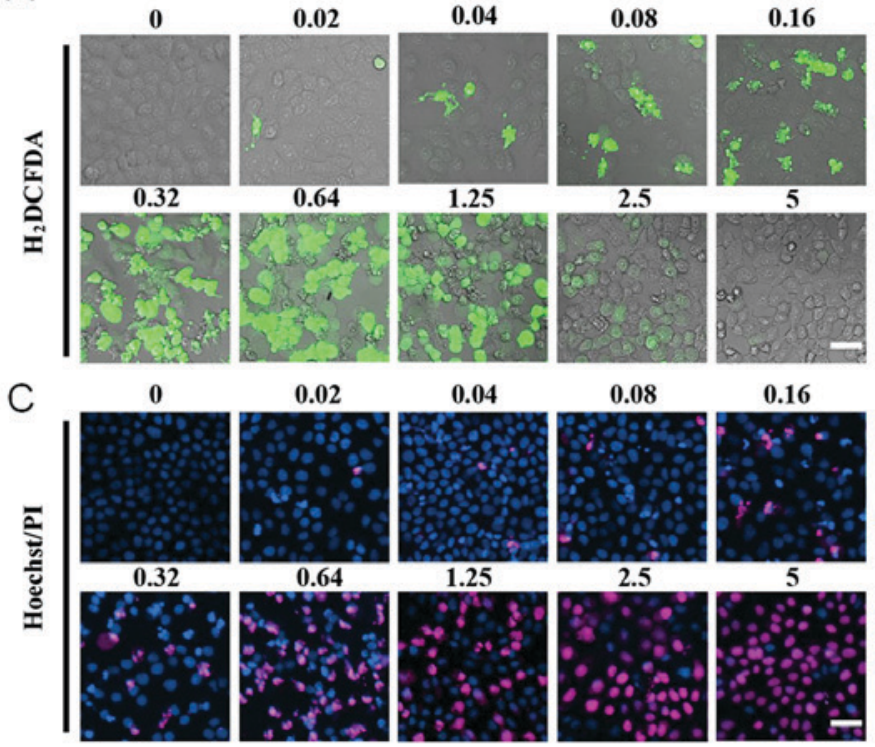

$\mathrm{B}$

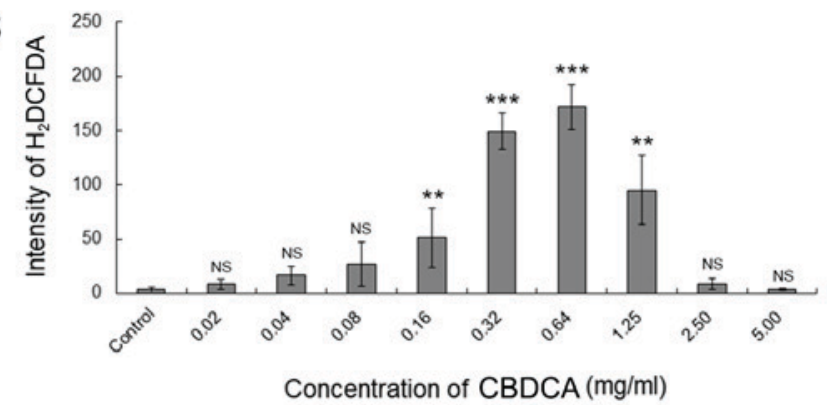

D

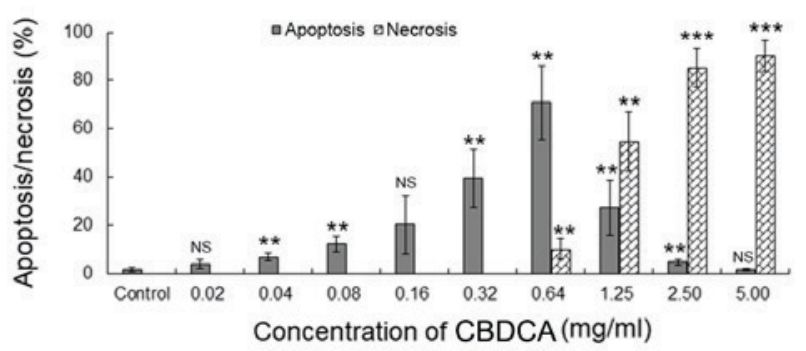

Figure 2. CBDCA may promote the production of ROS and apoptosis in HN-3 cells. (A) The HN-3 cells were treated with indicated doses of dimethyl sulfoxide (control) or CBDCA, and $2 \mu \mathrm{M} \mathrm{H}_{2}$ DCFDA successively. Subsequently, a laser scanning confocal microscope was used to observe the green intensity of $\mathrm{H}_{2}$ DCFDA to inspect the expression level of ROS. Scale bar, $50 \mu \mathrm{m}$. (B) Quantified expression of ROS in the HN-3 cells, which were analyzed by fluorescent staining using $\mathrm{H}_{2}$ DCFDA. (C) The aforementioned HN-3 cells were also used to conduct cell fluorescent staining to detect the ratio between apoptosis and necrosis through staining with Hoechst $33342(2 \mu \mathrm{g} / \mathrm{ml} ; 30 \mathrm{~min})$ and PI (2 $\mu \mathrm{g} / \mathrm{ml} ; 10 \mathrm{~min})$. Scale bar, $20 \mu \mathrm{m}$. (D) Quantified ratio of apoptosis/necrosis in HN-3 cells, which were analyzed by fluorescent staining using Hoechst/PI. The data were expressed as mean \pm standard deviation, ${ }^{* *} \mathrm{P}<0.01$ and ${ }^{* * *} \mathrm{P}<0.001$ vs. control. ROS, reactive oxygen species; CBDCA, carboplatin; PI, propidium iodide; NS, not significant; $\mathrm{H}_{2}$ DCFDA, 2',7'-dichlorodihydrofluorescein diacetate.

the concentrations of $\mathrm{H}_{2} \mathrm{O}_{2}$ and $\mathrm{GSH}$ were selected as 0.2 and $5 \mathrm{mM}$, respectively, guaranteeing a notable effect on cell viability. The results in Fig. 3 demonstrate that treatment with GSH or $\mathrm{H}_{2} \mathrm{O}_{2}$ alone had negligible effects on the viability of $\mathrm{HN}-3$ cells, but the combination treatment of CBDCA with GSH almost completely blocked the inhibitory effects of CBDCA on cell viability compared with the treatment of CBDCA $(0.08 \mathrm{mg} / \mathrm{ml})$ alone $(\mathrm{P}<0.01)$, whereas the inhibitory effects were significantly promoted by the combination treatment of CBDCA with $\mathrm{H}_{2} \mathrm{O}_{2}(\mathrm{P}<0.01)$. These data indicated that the ROS levels were increased by the oxidant $\mathrm{H}_{2} \mathrm{O}_{2}$ and promoted HN-3 cell apoptosis induced by CBDCA, whereas the deoxidizer GSH had the opposite effects. These results confirmed that CBDCA induces the apoptosis of HN-3 cells by increasing the production of ROS.

Combination treatment of CBDCA with GSH blocks the inhibitory role of $C B D C A$ on the migration of $H N-3$ cells. The antitumor effects of CBDCA not only reflected suppression of cancer cell viability, but also their migration ability. Therefore, following combined treatment of HN-3 cells with CBDCA and $\mathrm{GSH}$ or $\mathrm{H}_{2} \mathrm{O}_{2}$, their cell migration ability was assessed using a wound-healing assay. Although statistically significant at $24 \mathrm{~h}$ treatment, GSH treatment alone could only slightly affect the cell migration ability, whereas treatment of CBDCA or $\mathrm{H}_{2} \mathrm{O}_{2}$ (except $\mathrm{H}_{2} \mathrm{O}_{2}$ treatment for $12 \mathrm{~h}$ ) alone significantly inhibited the migration ability compared with the cells without any treatment (Fig. 4A and B). However, when HN-3 cells were treated with a combination of CBDCA and GSH, the inhibitory effects of CBDCA on cell migration ability were blocked by GSH, whereas the combined treatment of CBDCA and $\mathrm{H}_{2} \mathrm{O}_{2}$ promoted migration.

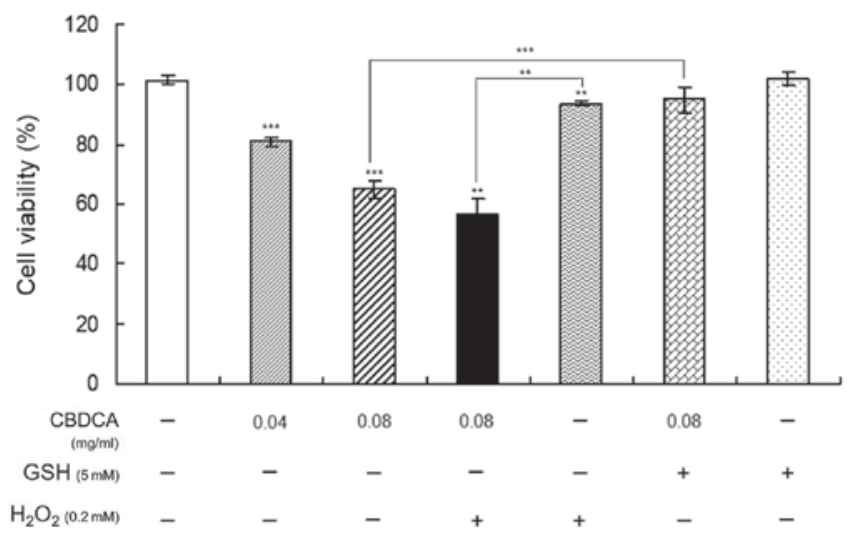

Figure 3. Combined treatment of $\mathrm{GSH}$ or $\mathrm{H}_{2} \mathrm{O}_{2}$ may block or promote the suppressive effect of CBDCA on the proliferation of $\mathrm{HN}-3$ cells. The indicated doses of dimethyl sulfoxide (control), CBDCA, GSH or $\mathrm{H}_{2} \mathrm{O}_{2}$ were added to $\mathrm{HN}-3$ cells and further cultured in a cell incubator at $37^{\circ} \mathrm{C}$ in an atmosphere containing $5 \% \mathrm{CO}_{2}$ for $48 \mathrm{~h}$. Subsequently, an MTT assay was used to detect the cell viability. Cell viability was calculated according to the following equation: Cell viability $(\%)=($ mean absorbance in the treatment group/mean absorbance in the control group) $x 100$. The data were expressed as mean \pm standard deviation, ${ }^{* *} \mathrm{P}<0.01$ and ${ }^{* * *} \mathrm{P}<0.001$ vs. control or as indicated. GSH, glutathione; CBDCA, carboplatin.

Combination treatment of CBDCA and GSH inhibits the apoptosis induced by $C B D C A$ in $H N-3$ cells. Up to this point, the present results indirectly demonstrated that CBDCA caused the apoptosis of HN-3 cells by increasing the release of ROS. Subsequently, the present study aimed to directly verify this phenomenon. Therefore, HN-3 cells treated as aforementioned were collected and lysed to obtain total proteins, which were subsequently analyzed by western blotting. The results demonstrated that, compared with the non-treatment group, CBDCA 

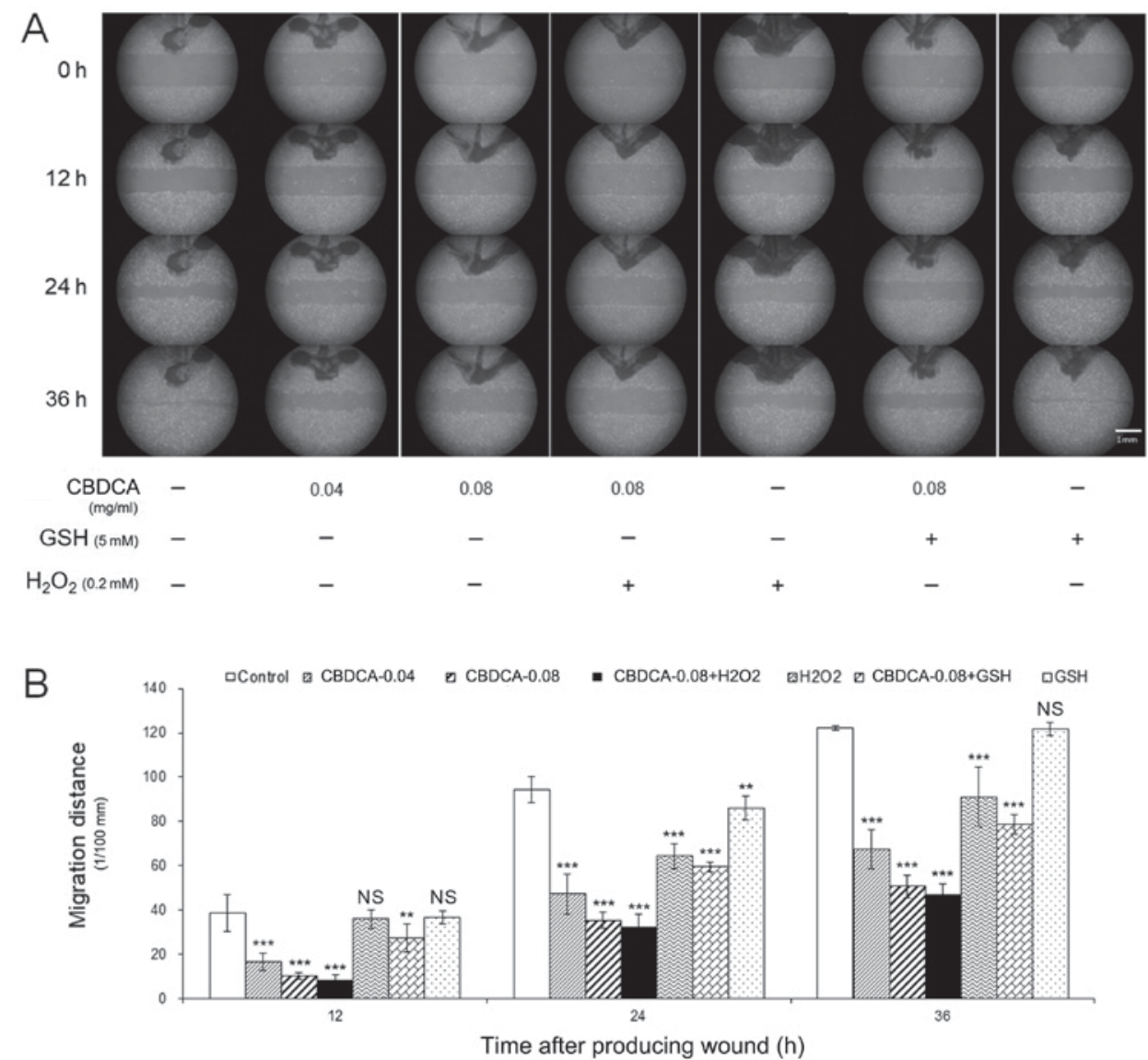

Figure 4. Combined treatment of GSH or $\mathrm{H}_{2} \mathrm{O}_{2}$ may block or promote the inhibitory role of CBDCA on the migration of HN-3 cells. (A) The HN-3 cells were seeded into six-well plates, and then indicated doses of CBDCA, GSH or $\mathrm{H}_{2} \mathrm{O}_{2}$ were added, and further cultured in a cell incubator at $37^{\circ} \mathrm{C}$ in an atmosphere containing 5\% $\mathrm{CO}_{2}$ for 0,24 or $48 \mathrm{~h}$. Subsequently, a wound-healing assay was performed to investigate the effect of CBDCA, $\mathrm{GSH}_{\text {or }} \mathrm{H}_{2} \mathrm{O}_{2}$ on the migration ability of HN-3 cells. (B) The statistical analysis for the migration ability of the aforementioned HN-3 cells. The data were expressed as mean \pm standard deviation, ${ }^{* * *} \mathrm{P}<0.01$ and ${ }^{* * *} \mathrm{P}<0.001$ vs. control. CBDCA, carboplatin; GSH, glutathione; NS, not significant.
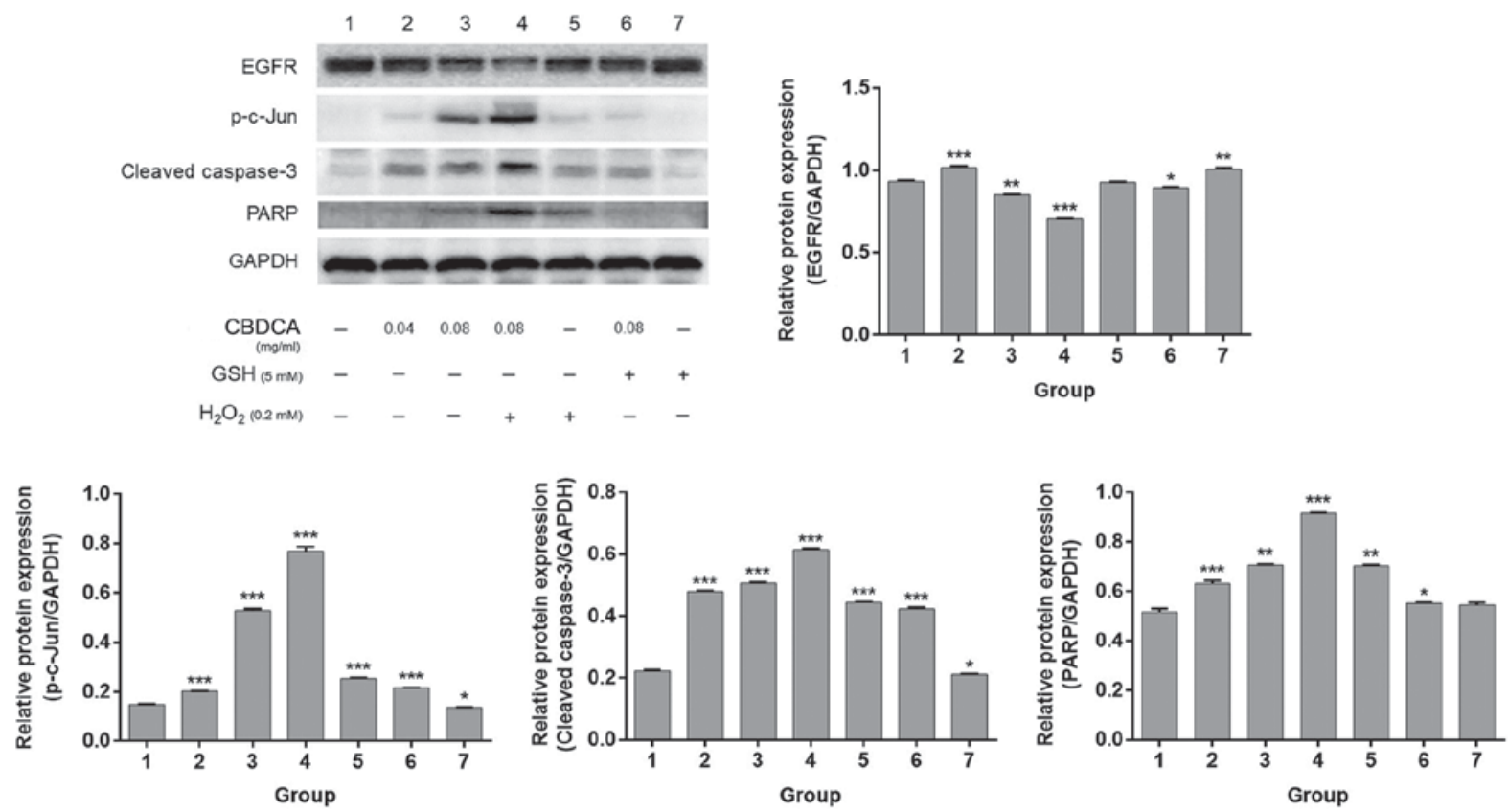

Figure 5. Combined treatment of GSH or $\mathrm{H}_{2} \mathrm{O}_{2}$ may inhibit or promote the apoptosis induced by CBDCA in $\mathrm{HN}-3$ cells. The indicated doses of CBDCA, GSH or $\mathrm{H}_{2} \mathrm{O}_{2}$ were added to $\mathrm{HN}-3$ cells and further cultured in a cell incubator at $37^{\circ} \mathrm{C}$ in an atmosphere containing $5 \% \mathrm{CO}_{2}$ for $24 \mathrm{~h}$. These cells were collected and lysed to acquire total proteins to inspect the protein expression levels of EGFR, p-c-Jun, PARP and cleaved-caspase-3 using western blotting. GAPDH was used to confirm the equal amount of proteins loaded in each lane. Membranes were scanned with ImageJ to quantify band intensity. The data were expressed as mean \pm standard deviation, ${ }^{\prime} \mathrm{P}<0.05,{ }^{* * *} \mathrm{P}<0.01$ and ${ }^{* * * *} \mathrm{P}<0.001$ vs. lane 1 . EGFR, epidermal growth factor receptor; PARP, poly(ADP-ribose) polymerase; CBDCA, carboplatin; GSH, glutathione; p-c-Jun, phosphorylated c-Jun. 
and $\mathrm{H}_{2} \mathrm{O}_{2}$ treatment alone significantly $(\mathrm{P}<0.05)$ increased the expression levels of p-c-Jun, caspase-3 and PARP, which represented the degree of apoptosis. Additionally, CBDCA $(0.08 \mathrm{mg} / \mathrm{ml})$ treatment inhibited the expression of EGFR which reflects the proliferation ability $(\mathrm{P}<0.05$; Fig. 5). The combination treatment of CBDCA and $\mathrm{H}_{2} \mathrm{O}_{2}$ exacerbated this trend, compared with CBDCA treatment alone, whereas the combination treatment of CBDCA and GSH impaired this effect (Fig. 5). These data demonstrated that the combined application of CBDCA and $\mathrm{H}_{2} \mathrm{O}_{2}$ enhanced the levels of apoptosis induced by CBDCA in HN-3 cells, whereas GSH blocked these effects. These results support the previous observations that CBDCA increases the production of ROS in HN-3 cells, causing apoptosis.

\section{Discussion}

Platinum anticancer agents, including cisplatin and CBDCA, have been frequently used as chemotherapies to treat various cancer types including bladder cancer and malignant melanoma (33). They enter cells with the assistance of copper transporter 1 , and are converted into their corresponding aqua complexes, thereby crosslinking DNA to exhibit antitumor activity $(34,35)$. Among these types of agents, CBDCA, a second-generation platinum anti-cancer agent, was developed to overcome the side effects of cisplatin, including nephrotoxicity and neurotoxicity (36). CBDCA has notable antitumor activity against a variety of cancer types, including ovarian and small-cell lung cancer $(31,32)$. Previous studies have demonstrated that the oxidative stress caused by ROS promoted the apoptosis of LSCC cells through a number of functional mechanisms $(16,17,37)$. For example, in 2009 it was reported that the combined treatment of 9-HPbD and CBDCA caused increased cytotoxicity and resulted in apoptosis of a greater number of LSCC cells (17). Additionally, by reducing their dosage, reduced toxicity was observed in normal cells (17). In 2010, one study demonstrated that 9-HPbD caused oxidative stress, which resulted in the increased production of ROS and apoptosis of HN-3 cells through the extrinsic apoptotic pathway, and endoplasmic reticulum stress was also involved in this process (16). In addition, in 2016, a study demonstrated that 9-HPbD $\alpha$-based photodynamic therapy promoted apoptosis and necrosis, and suppressed cell migration, which was directly mediated by ROS accumulation (37). In light of these results, the present study focused on understanding the molecular mechanisms involved in the antitumor effects of a number of traditional drugs including CBDCA for the treatment of LSCC, with the goal of determining novel treatment strategies for this disease. In the present study, the aim was to determine if the mechanism underlying $\mathrm{HN}-3$ cell death was high expression of ROS due to CBDCA.

Although CBDCA has been used to treat various malignant tumor types including non-small cell lung cancer and ovarian cancer for $\sim 30$ years $(20,21,24)$, only a limited number of studies have been conducted on its use in the treatment of LSCC $(17,26,38)$. To the best of our knowledge, our research group was the first to investigate the antitumor effects and mechanisms of CBDCA in LSCC $(17,26)$. Therefore, the present study would be of notable significance for the development of novel LSCC treatments.
In the present study, it was verified that CBDCA may exert antitumor effects in LSCC. The results revealed its anticancer effects against $\mathrm{HN}-3$ cells in a time- and dose-dependent manner. CBDCA exerts its effects through numerous different molecular mechanisms, including apoptosis, necrosis and autophagy may be triggered by different apoptotic signaling pathways. Accordingly, the aim of the present study was also to investigate whether the mechanism of the antitumor effects of CBDCA were similar to those of 9-HPbD. Therefore, the expression level of ROS and the apoptosis/necrosis rate of HN-3 cells were measured following treatment with different concentrations. The results indicated that the ROS concentration in HN-3 cells increased as the concentration of CBDCA increased, but additional increases in CBDCA concentration resulted in the reduced expression of ROS. This trend was also observed for the degree of apoptosis of HN-3 cells. Notably, the optimum concentration for cell apoptosis was identical to that obtained from the detection of ROS concentration. These results indicated that apoptosis induced by CBDCA in $\mathrm{HN}-3$ cells is associated with ROS production.

In a previous study, the induced generation of ROS by treatment with CBDCA was reported and demonstrated to some extent (26). However, the direct association between CBDCA treatment and generation of ROS has not been established. Therefore, in the present study, CBDCA with GSH, a reductant that inhibits the expression of ROS, or $\mathrm{H}_{2} \mathrm{O}_{2}$, an oxidant that promotes the release of ROS $(39,40)$, were combined to treat HN-3 cells and then their viability, migration ability and apoptosis state was assessed. As expected, the results demonstrated that the combined treatment of CBDCA with $\mathrm{H}_{2} \mathrm{O}_{2}$ synergistically suppressed the migration ability and viability, and enhanced the apoptosis of HN-3 cells, compared with CBDCA treatment alone, whereas the combined treatment of CBDCA and GSH produced opposite results. These results indicated that CBDCA promotes apoptosis by the excessive production of ROS in human LSCC cells. Notably, one of the limitations of the present study was that all studies were performed based on HN-3 cells. In future studies, the research scope would be extended by additionally utilizing LSCC cell lines, including TU212 and TU686, and including a number of normal control cell lines.

In conclusion, the results of the present study demonstrated that CBDCA exerts promising antitumor effects in LSCC cells, inhibits cell proliferation and migration, and promotes apoptosis through the excessive expression of ROS in LSCC cells. These results may provide a novel therapeutic strategy for the treatment of LSCC.

\section{Acknowledgements}

Not applicable.

\section{Funding}

The present study was supported by the National Natural Science Foundation of China (grant no. 81172557) and the Project of Shanghai Municipal Health and Family Planning Commission (grant no. 201640104), and partially supported by Leading Foreign Research Institute Recruitment Program 
through the National Research Foundation of Korea funded by the Ministry of Education, Science and Technology (grant no. 2012K1A4A3053142), and Beckman Laser Institute Korea, Dankook University.

\section{Availability of data and materials}

The datasets used and/or analyzed during the current study are available from the corresponding author on reasonable request.

\section{Authors' contributions}

PJH and HTW made substantial contributions to the concept and design of the present study, and the examination of the manuscript. PJH, RFG and WJM conducted experiments and produced the manuscript. PSC and JCA conducted experiments and analyzed the experimental data.

\section{Ethics approval and consent to participate}

Not applicable.

\section{Patient consent for publication}

Not applicable.

\section{Competing interests}

The authors declare that they have no competing interests.

\section{References}

1. Zhang W, Yan Y, Gu M, Wang X, Zhu H, Zhang S and Wang W: High expression levels of Wnt5a and Ror2 in laryngeal squamous cell carcinoma are associated with poor prognosis. Oncol Lett 14: 2232-2238, 2017.

2. Siegel R, Naishadham D and Jemal A: Cancer statistics, 2013. CA Cancer J Clin 63: 11-30, 2013.

3. Riga M, Chelis L, Danielides V, Vogiatzaki T, Pantazis TL and Pantazis D: Systematic review on T3 laryngeal squamous cell carcinoma; still far from a consensus on the optimal organ preserving treatment. Eur J Surg Oncol 43: 20-31, 2017.

4. Shen Z, Cao B, Lin L, Zhou C, Ye D, Qiu S, Li Q and Cui X: The clinical signification of claudin-11 promoter hypermethylation for laryngeal squamous cell carcinoma. Med Sci Monit 23: 3635-3640, 2017.

5. Jemal A, Siegel R, Ward E, Hao Y, Xu J and Thun MJ: Cancer statistics, 2009. CACancerJ Clin 59: 225-249, 2009.

6. Dirix P, Lambrecht M and Nuyts S: Radiotherapy for laryngeal squamous cell carcinoma: Current standards. Expert Rev Anticancer Ther 10: 1461-1469, 2010.

7. Xia CX,Zhu Q,Zhao HX, Yan F,Li SL and Zhang SM: Usefulness of ultrasonography in assessment of laryngeal carcinoma. Brit J Radiol 86: 20130343, 2013.

8. Wang B, Lv K, Chen W, Jing Z, Jie L, Wu J, Li Z, Hao Q, Wong TS, Yang W, et al: miR-375 and miR-205 regulate the invasion and migration of laryngeal squamous cell carcinoma synergistically via AKT-mediated EMT. Biomed Res Int 2016: $9652789,2016$.

9. Phang CW, Karsani SA and Abd Malek SN: Induction of apoptosis and cell cycle arrest by flavokawain C on HT-29 human colon adenocarcinoma via enhancement of reactive oxygen species generation, upregulation of p21, p27 and GADD153, and inactivation of inhibitor of apoptosis proteins. Pharmacogn Mag 13 (Suppl 2): S321-S328, 2017.

10. Nakayama K, Murata S, Ito H, Iwasaki K, Villareal MO, Zheng YW, Matsui H, Isoda H and Ohkohchi N: Terpinen-4-ol inhibits colorectal cancer growth via reactive oxygen species. Oncol Lett 14: 2015-2024, 2017.
11. Allison SE, Chen Y, Petrovic N, Zhang J, Bourget K, Mackenzie PI and Murray M: Activation of ALDH1A1 in MDA-MB-468 breast cancer cells that over-express CYP2J2 protects against paclitaxel-dependent cell death mediated by reactive oxygen species. Biochem Pharmacol 143: 79-89, 2017.

12. Choi YH: Diallyl trisulfide induces apoptosis and mitotic arrest in AGS human gastric carcinoma cells through reactive oxygen species-mediated activation of AMP-activated protein kinase. Biomed Pharmacother 94: 63-71, 2017.

13. Chang YT, Huang CY, Tang JY, Liaw CC, Li RN, Liu JR, Sheu JH and Chang HW: Reactive oxygen species mediate soft corals-derived sinuleptolide-induced antiproliferation and DNA damage in oral cancer cells. Onco Targets Ther 10: 3289-3297, 2017.

14. Kim KY, Park KI, Kim SH, Yu SN, Park SG, Kim YW, Seo YK, Ma JY and Ahn SC: Inhibition of autophagy promotes salinomycin-induced apoptosis via reactive oxygen species-mediated PI3K/AKT/mTOR and ERK/p38 MAPK-dependent signaling in human prostate cancer cells. Int J Mol Sci 18: 1088, 2017.

15. Shagieva G, Domnina L, Makarevich O, Chernyak B, Skulachev V and Dugina V: Depletion of mitochondrial reactive oxygen species downregulates epithelial-to-mesenchymal transition in cervical cancer cells. Oncotarget 8: 4901-4913, 2017.

16. He P, Ahn JC, Shin JI and Chung PS: Photoactivation of 9-hydroxypheophorbide alpha triggers apoptosis through the reactive oxygen species-mediated mitochondrial pathway and endoplasmic reticulum stress in AMC-HN-3 laryngeal cancer cells. Int J Oncol 36: 801-808, 2010.

17. He P, Ahn JC, Shin JI, Hwang HJ, Kang JW, Lee SJ and Chung PS: Enhanced apoptotic effect of combined modality of 9-hydroxypheophorbide alpha-mediated photodynamic therapy and carboplatin on AMC-HN-3 human head and neck cancer cells. Oncol Rep 21: 329-334, 2009.

18. Baek MW, Cho HS, Kim SH, Kim WJ and Jung JY: Ascorbic acid induces necrosis in human laryngeal squamous cell carcinoma via ROS, PKC, and calcium signaling. J Cell Physiol 232: 417-425, 2017.

19. Castrellon AB, Pidhorecky I, Valero V and Raez LE: The role of carboplatin in the neoadjuvant chemotherapy treatment of triple negative breast cancer. Oncol Rev 11: 324, 2017.

20. de Castria TB, da Silva EM, Gois AF and Riera R: Cisplatin versus carboplatin in combination with third-generation drugs for advanced non-small cell lung cancer. Cochrane Database Syst Rev 16: CD009256, 2013.

21. Collins IM, Roberts-Thomson R, Faulkner D, Rischin D, Friedlander M and Mileshkin L: Carboplatin dosing in ovarian cancer: Problems and pitfalls. Int J Gynecol Cancer 21: 1213-1218, 2011.

22. Chikazawa K, Netsu S and Konno R: Outcomes of concurrent radiotherapy and weekly paclitaxel/carboplatin therapy in cervical cancer: A retrospective study. Eur J Gynaecol Oncol 37: 511-516, 2016.

23. Pisters KM, Vallières E, Crowley JJ, Franklin WA, Bunn PA Jr, Ginsberg RJ, Putnam JB Jr, Chansky K and Gandara D: Surgery with or without preoperative paclitaxel and carboplatin in early-stage non-small-cell lung cancer: Southwest Oncology Group Trial S9900, an intergroup, randomized, phase III trial. J Clin Oncol 28: 1843-1849, 2010.

24. Ho GY, Woodward N and Coward JI: Cisplatin versus carboplatin: Comparative review of therapeutic management in solid malignancies. Crit Rev Oncol Hematol 102: 37-46, 2016.

25. Cheng CF, Juan SH, Chen JJ, Chao YC, Chen HH, Lian WS, Lu CY, Chang CI, Chiu TH and Lin H: Pravastatin attenuates carboplatin-induced cardiotoxicity via inhibition of oxidative stress associated apoptosis. Apoptosis 13: 883-894, 2008.

26. Mao WJ, Zhang HK, Shen B and Pei-Jie HE: Role of reactive oxygen series generation in the apoptosis of HN-3 human laryngeal carcinoma cells induced by carboplatin. Chin J Ophthalmol Otorhinolaryngol 15: 384-387, 2015.

27. Kim SY, Chu KC, Lee HR, Lee KS and Carey TE: Establishment and characterization of nine new head and neck cancer cell lines. Acta Otolaryngol 117: 775-784, 1997.

28. Morin $\mathrm{C}$ and Fortin S: Docosahexaenoic acid monoglyceride increases carboplatin activity in lung cancer models by targeting EGFR. Anticancer Res 37: 6015-6023, 2017.

29. Ryu H, Song IC, Choi YS, Yun HJ, Jo DY, Kim JM, Ko YB and Lee HJ: ERCC1 expression status predicts the response and survival of patients with metastatic or recurrent cervical cancer treated via platinum-based chemotherapy. Medicine (Baltimore) 96: e9402, 2017. 
30. Bayés M, Rabasseda X and Prous JR: Gateways to clinical trials. Methods Find Exp Clin Pharmacol 29: 697-735, 2007.

31. Yazawa H, Hiraiwa T, Ito F and Fujimori K: Long-term recurrence-free survival of a patient with advanced pure primary ovarian squamous cell carcinoma treated with dose-dense paclitaxel combined with carboplatin. Obstet Gynecol Sci 60: 587-592, 2017.

32. Han S, Hong Y, Liu T, Wu N and Ye Z: The efficacy and safety of paclitaxel and carboplatin with versus without bevacizumab in patients with non-small-cell lung cancer: A systematic review and meta-analysis. Oncotarget 9: 14619-14629, 2017.

33. Liu JJ, Kim Y, Yan F, Ding Q, Ip V, Jong NN, Mercer JF and Mckeage MJ: Contributions of rat Ctrl to the uptake and toxicity of copper and platinum anticancer drugs in dorsal root ganglion neurons. Biochem Pharmacol 85: 207-215, 2013.

34. Knox RJ, Friedlos F, Lydall DA and Roberts JJ: Mechanism of cytotoxicity of anticancer platinum drugs: Evidence that cis-di amminedichloroplatinum(II) and cis-diammine-(1,1-cyclobutanedicarboxylato)platinum(II) differ only in the kinetics of their interaction with DNA. Cancer Res 46: 1972-1979, 1986.

35. McWhinney SR, Goldberg RM and McLeod HL: Platinum neurotoxicity pharmacogenetics. Mol Cancer Ther 8: 10-16, 2009.

36. Ardizzoni A, Boni L, Tiseo M, Fossella FV, Schiller JH, Paesmans M, Radosavljevic D, Paccagnella A, Zatloukal P, Mazzanti P, et al: Cisplatin-versus carboplatin-based chemotherapy in first-line treatment of advanced non-small-cell lung cancer: An individual patient data meta-analysis. J Natl Cancer Inst 99: 847-857, 2007.
37. He P, Shen B, Chung PS, Ahn JC and Zhou L: Photosensitizer effect of 9-hydroxypheophorbide $\alpha$ on diode laser-irradiated laryngeal cancer cells: Oxidative stress-directed cell death and migration suppression. Oncol Lett 12: 1889-1895, 2016.

38. Nishimura G, Tsukuda M, Mikami Y, Matsuda H, Horiuchi C, Taguchi T, Takahashi M, Kawakami M, Watanabe $M$, Niho T, et al: Efficacy of concurrent chemoradiotherapy for $\mathrm{T} 1$ and T2 laryngeal squamous cell carcinoma regarding organ preservation. Anticancer Res 29: 661-666, 2009.

39. Park WH and You BR: Antimycin A induces death of the human pulmonary fibroblast cells via ROS increase and GSH depletion. Int J Oncol 48: 813-820, 2016.

40. Singsai K, Akaravichien T, Kukongviriyapan V and Sattayasai J: Protective effects of streblus asper leaf extract on $\mathrm{H} 2 \mathrm{O} 2$-induced ROS in SK-N-SH Cells and MPTP-induced parkinson's disease-like symptoms in C57BL/6 mouse. Evid Based Complement Alternat Med 2015: 970354, 2015.

This work is licensed under a Creative Commons Attribution-NonCommercial-NoDerivatives 4.0 International (CC BY-NC-ND 4.0) License. 